\title{
Inflammatory Cytokines and Antipsychotic-Induced Weight Gain: Review and Clinical Implications
}

\author{
Trehani M. Fonseka ${ }^{a-c}$ Daniel J. Müller ${ }^{c}$ Sidney H. Kennedy ${ }^{a, b}$ \\ ${ }^{a}$ Department of Psychiatry, University Health Network, University of Toronto, ${ }^{b}$ Department of Psychiatry, St. \\ Michael's Hospital, University of Toronto, and 'Pharmacogenetics Research Clinic, Campbell Family Mental Health \\ Research Institute, Centre for Addiction and Mental Health, University of Toronto, Toronto, Ont., Canada
}

\section{Key Words}

Cytokines - Inflammation · Antipsychotic-induced weight gain · Schizophrenia $\cdot$ Side effect

\begin{abstract}
Antipsychotic medications (APs), particularly second-generation APs, are associated with significant weight gain in schizophrenia patients. Recent evidence suggests that the immune system may contribute to antipsychotic-induced weight gain (AIWG) via AP-mediated alterations of cytokine levels. Antipsychotics with a high propensity for weight gain, such as clozapine and olanzapine, influence the expression of immune genes, and induce changes in serum cytokine levels to ultimately down-regulate neuroinflammation. Since inflammatory cytokines are normally involved in anorexigenic responses, reduced inflammation has been independently shown to mediate changes in feeding behaviours and other metabolic parameters, resulting in obesity. Genetic variation in pro-inflammatory cytokines is also associated with both general obesity and weight change during AP treatment, and thus, may be implicated in the pharmacogenetics of AIWG. At this time, preliminary data support a cytokine-mediated model of AIWG which may have clinical utility in developing more effective metabolic monitoring
\end{abstract}

guidelines and prevention measures. However, further research is still needed to clearly elucidate the validity of this immune model. This article reviews the evidence implicating inflammatory cytokines in AIWG and its potential clinical relevance.

(c) 2016 S. Karger AG, Basel

\section{Introduction}

Antipsychotic-induced weight gain (AIWG) is a common side effect which, according to some measures, affects up to $72 \%$ of schizophrenia patients receiving acute or maintenance treatment [1]. AIWG has been documented since the advent of chlorpromazine with reports of steadily increasing weight with treatment that rapidly declines upon drug cessation $[2,3]$. AIWG appears to occur more often with second-generation antipsychotics (SGAs) than first-generation antipsychotics (FGAs), and with greater probability for some SGAs than others $[4,5]$. In a review by Lett et al. [4], clozapine and olanzapine were identified as conferring the highest risk of weight

D.J.M. and S.H.K. co-shared senior authorship.

\section{KARGER}

E-Mail karger@karger.com www.karger.com/mnp
(C) 2016 S. Karger AG, Basel

2296-9209/16/0021-0001\$39.50/0
Sidney H. Kennedy, MD

Department of Psychiatry, University Health Network

399 Bathurst Street, Main Pavilion, 9-329

Toronto, ON M5T 2S8 (Canada)

E-Mail sidney.kennedy@uhn.ca 


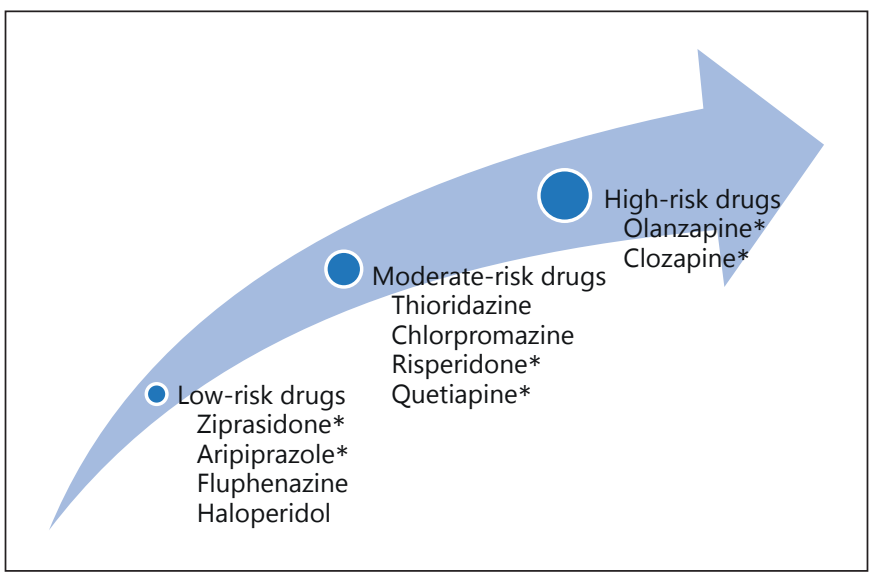

Fig. 1. Weight change propensities of antipsychotic treatments. Antipsychotics are categorized according to a low, moderate, or high propensity to induce weight gain in patients. The varying propensities of antipsychotics to induce AIWG may depend on differences in their immunomodulatory profiles. Drugs are listed in the order from highest to lowest weight-inducing potential per category. Asterisk indicates SGA.

gain among SGAs, with quetiapine and risperidone having intermediate risk, and aripiprazole and ziprasidone having minimal risk, according to mean weight change values (fig. 1). While most patients treated with antipsychotics gain weight, some studies also suggest that antipsychotic medications (APs) can induce clinically significant weight loss in up to $10 \%$ of patients [6].

AIWG is a leading contributor to AP non-compliance, and a major risk factor for obesity, as well as other metabolic (e.g. dyslipidaemia, hyperglycaemia, diabetes mellitus) and vascular (e.g. cardiovascular and cerebrovascular disease, arterial hypertension, ventricular arrhythmias) abnormalities, and premature mortality $[7,8]$. In addition, APs have the potential to exacerbate pre-existing metabolic irregularities that are otherwise observed at lower frequencies and/or severities within untreated schizophrenia $[9,10]$. For example, Zhang et al. [9] identified significant increases in subcutaneous and intra-abdominal fat, in addition to elevated levels of leptin, circulating lipids, and non-fasting glucose after 10 weeks of AP treatment in previously untreated schizophrenia patients. In a meta-analysis by Mitchell et al. [10], metabolic irregularities such as obesity ( 52.7 vs. $26.6 \%$ ), elevated triglycerides (41.1 vs. 16.9\%), low levels of high-density lipoproteins ( 44.7 vs. $20.4 \%$ ), high blood pressure (39.7 vs. $24.3 \%)$, diabetes mellitus (12.8 vs. $2.1 \%$ ), and hyperglycaemia ( 27.8 vs. $6.4 \%)$ occurred more frequently in treat- ed as compared to untreated schizophrenia patients, respectively. Beyond psychotic disorders, AIWG has also been observed in other AP-treated psychiatric populations, such as bipolar disorder [11], treatment-resistant major depressive disorder [12], mental retardation and autistic disorder [13], and Tourette's syndrome [14], suggesting that AIWG occurs independently of schizophrenia as an underlying condition.

Despite these clinically significant metabolic outcomes, the mechanisms implicated in AIWG are not fully understood. Nevertheless, various biological mechanisms have been linked to the orexigenic effects of antipsychotics, including neurotransmitter systems (e.g. serotoninergic, histaminergic, adrenergic, dopaminergic), neuropeptides [e.g. leptin, ghrelin, neuropeptide Y (NPY)], and neuroendocrine systems (e.g. insulin, prolactin; for review, refer to Wysokinski and Kloszewska [15]). Recent evidence also suggests that the immune system may at least partially contribute to this metabolic phenotype, particularly via AP-induced alterations of cytokine levels. More specifically, APs have been shown to influence the expression of cytokines to ultimately downregulate neuroinflammatory signatures $[16,17]$. An increase in inflammatory cytokines is normally involved in anorexigenic responses, while reduced inflammation has been independently shown to mediate changes in feeding behaviours and other metabolic parameters which can lead to obesity [18-20]. Genetic variation in pro-inflammatory cytokines is also associated with both general obesity [21-23], and weight change during AP treatment [24], and thus, may be implicated in the pharmacogenetics of AIWG. Although limited research has examined the direct link between cytokines and AIWG, based on these preliminary findings, we propose a cytokine-mediated immune model of AIWG which will be further outlined within this review.

\section{The Role of Cytokines in Energy Homeostasis}

\section{Biological Properties of Cytokines}

Cytokines are pleiotropic proteins involved in host regulation of both immunological and non-immunological processes, and are classified as either pro-inflammatory or anti-inflammatory in function based on their ability to either augment or suppress the immune response [25]. Cytokines are produced by a variety of cell types within the periphery (e.g. endothelial cells, monocytes/ macrophages, dendritic cells, natural killer cells, and $\mathrm{T}$ cells) and the central nervous system (CNS; e.g. astro- 
cytes, microglia), where they function as chemical messengers [26-28].

In the periphery, cytokines (and other immune factors) are released by phagocytic cells upon infection [27, 29-31], and once the pathogen is cleared, there is a shift toward anti-inflammatory signalling in order to resolve inflammation and restore homeostasis [32]. In the CNS, microglia and astrocytes primarily regulate the initiation and termination of the inflammatory response [33]. Microglia are resident macrophages of the CNS that continuously survey the brain for neuronal damage, plaques, and microbes, and provide an immediate response to even minor central pathology [27]. Once activated, microglia engage in a variety of functions including phagocytosis and antigen presentation of invading microbes, secretion of oxidative stress markers like reactive oxygen species (ROS) and reactive nitrogen species, and production of cyclooxygenase (COX)-2, prostaglandin $\mathrm{E}_{2}$, and inflammatory cytokines [34-38]. Although astrocytes can secrete pro-inflammatory mediators, they primarily produce anti-inflammatory factors $[38,39]$. Astrocytes also have inhibitory and stimulatory effects on microglia depending on the internal immune state [27].

In addition to centrally produced factors, peripheral cytokines can also access the CNS through multiple humoral pathways that act in parallel, including: (1) passive transport at disrupted regions of the blood-brain barrier (BBB) [40] or through BBB-deficient choroid plexuses and circumventricular organs [41-43], (2) active transport via saturable transport molecules $[44,45]$, and (3) binding to cerebral endothelial cells to stimulate release of secondary inflammatory messengers [46-48]. Immune information is also transmitted to the brain using rapid neural pathways which activate primary afferent nerve fibres in response to peripheral cytokine release [49-51]. Once immune information from the periphery reaches the brain, it is reconstituted in the CNS via central cytokine release [52].

The immune capabilities of different cytokines are highly redundant, and ultimately lead to the stimulation of multiple cell types and the downstream production of inflammatory mediators $[1,53]$. Pro-inflammatory cytokines, such as interleukin (IL)-1, IL-2, IL-6, and tumour necrosis factor alpha (TNF- $\alpha$ ) augment the inflammatory cascade by recruiting leukocytes, activating inflammatory cells, and assisting with the elimination of invading pathogens $[26,27]$. Anti-inflammatory cytokines, such as IL-4, IL-5, IL-10, IL-1 receptor antagonist (IL-1RA), and soluble IL-2 receptor (sIL-2R), are reciprocally designed to down-regulate inflammation via immunosuppressive functions $[38,54]$.

Cytokines in Antipsychotic-Induced Weight Gain
Cytokines yield their effects by binding to specific cytokine receptors that are expressed on a variety of peripheral and central cells, and also exist in soluble form [55]. Some receptor subtypes serve as non-functional decoys (e.g. IL-1RII, sIL-2R) [26, 56, 57], while others enhance cytokine activity (e.g. sIL-6R) [26]. Inhibitory effects are also achieved by non-functional receptor antagonists (e.g. IL-1RA) which compete with cytokines for receptor binding sites [56]. Cytokine-receptor complexes are phosphorylated by Janus kinase (JAK) and Src kinases, and signal through pathways like JAK-STAT (signal transducer and activator of transcription), Ras/MAPK (mitogen activated protein kinase), and phosphoinositide-3-kinase (PI-3-kinase) to activate gene transcription and cellular activity [58].

Within this repertoire of immunological functions, cytokines play a key role in regulating energy homeostasis. This occurs primarily through central effects on feeding behaviours and other metabolic outcomes, both for immunological and non-immunological purposes.

\section{Cytokines and Hypothalamic Regulation of Energy Homeostasis}

AIWG results from AP-induced disruptions of central and peripheral energy homeostatic pathways, ultimately creating an imbalance favouring energy intake over energy expenditure [59]. Various genetic, neuronal, and hormonal factors are implicated in mediating this association through effects on appetite and satiety signals [60]. Of particular importance are hypothalamic homeostatic circuits which, in controlling food intake and thermoregulation, rely on peripherally released factors to monitor the body's energy stores and provide appetitestimulating (orexigenic) or appetite-diminishing (anorexigenic) signals to the CNS $[61,62]$. Although signals act at various CNS sites, the pathways converge onto the hypothalamus where they are integrated and cue central neurons to secrete relevant neuropeptides $[63,64]$. Inflammatory cytokines, along with leptin and insulin, are anorexigenic factors which function as adiposity signals to provide information on long-term energy stores to the hypothalamus under normal and pathological conditions [15]. To support this role, cytokines have action at central neurons, with particularly high receptor densities localized to the hippocampus and hypothalamus $[65,66]$. Cytokines are reciprocally regulated by various centrally released neurotransmitters and neuropeptides [66].

The primary CNS interface for these cytokines is the arcuate nucleus (ARC) of the hypothalamus which, due to an anatomical position near the base of the brain and

Mol Neuropsychiatry 2016;2:1-14 
poor BBB insulation, can directly interact with peripheral regulatory factors [15]. The ARC is responsible for reciprocally regulating two types of first-order neurons: (1) anorexigenic neurons co-expressing pro-opiomelanocortin (POMC) and cocaine- and amphetamine-regulated transcript (CART), and (2) orexigenic neurons coexpressing NPY, and agouti-related protein (AgRP) [67]. These neuropeptides act on second-order neurons which are localized to three primary hypothalamic sites: lateral/ perifornical hypothalamic area (LHA) or 'hypothalamic hunger centre', paraventricular nucleus (PVN) or 'hypothalamic satiety centre', and the ventromedial nucleus (VMN) which mediates satiation in response to blood glucose levels [15]. Signals transmitted to the LHA, PVN, and VMN are subsequently translated into autonomic, endocrine, and behavioural responses [64, 68].

\section{The Role of Cytokines in Weight Regulation}

\section{The Pathophysiological Role of Cytokines in Weight}

Regulation during Infection

During times of infection, the anorexigenic effects of inflammatory cytokines, which are typically observed as a reduction in food-motivated behaviours, food intake, and body weight $[69,70]$, occur as part of the acute phase response (APR) [71]. The APR is an integrated set of immune, endocrine, metabolic, behavioural, and neural alterations that are mounted by the innate immune system upon immediate recognition of an immunological insult $[72,73]$. In addition to anorexia, the APR can include fever, lethargy, altered plasma protein concentrations, and increased leukocyte counts [74]. APR reactions form a critically adaptive defence strategy that takes priority over regular homeostatic controls to provide short-term survival benefits to the host $[71,75]$. The survival benefits of anorexia can include: (1) reducing food scavenging behaviours to conserve energy and heat, (2) reducing access to food-derived micronutrients that can be used by pathogens to flourish, (3) limiting potentially harmful metabolic APR effects, and (4) promoting apoptosis of infected cells [72, 73, 75]. Murray and Murray [76] demonstrated these functions by showing that force-feeding infected mice to a normal energy intake increased mortality and reduced survival time compared to infected mice fed ad libitum. Similarly, Wing and Young [77] found that acutely starved mice infected with Listeria monocytogenes showed significantly less mortality than fed mice, further demonstrating the survival advantage of anorexic behaviours during times of acute infection.
The anorexigenic outcomes of the APR can be mimicked by externally administering inflammatory cytokines to the periphery or CNS, with synergistic effects occurring between cytokines in some cases [78-86]. The resultant alterations in feeding behaviours are typically observed as reductions in meal size, duration, and frequency, and longer inter-meal intervals [80, 85, 87]. Inflammatory cytokines have also been shown to influence metabolic rate, as observed by an increased rate of appearance and rate of metabolic clearance of glucose, in addition to other metabolic changes which include increased plasma levels of norepinephrine, cortisol, and glucagon, resting energy expenditure, plasma free fatty acid concentration, fat oxidation, and alterations of lowdensity lipoprotein metabolism [88, 89]. Moreover, cytokines can alter food preferences, as Aubert et al. [90] showed that rats treated with IL- $1 \beta$, in addition to having a reduced total caloric intake, consumed relatively more carbohydrates and less protein. Taste aversion is also observed following cytokine administration, but this does not appear to be a major component of anorexic action $[72,91]$. Nevertheless, anorexigenic responses can be attenuated using cytokine and/or cytokine receptor gene knock-out models $[92,93]$, or cytokine antagonism [87, 94-96]. Tolerance to chronic cytokine administration can develop with consequent restoration of normal food intake $[97,98]$, supporting that anorexic effects of cytokines are intended to be short-term. Beyond altering feeding behaviours, cytokines can also influence body weight through effects on energy expenditure such as by inducing changes in body temperature $[99,100]$.

\section{The Physiological Role of Cytokines in Normal Weight} Regulation

During normal fat accumulation and adipocyte enlargement, adipose tissue (particularly within visceral fat) becomes a site of active inflammation as it undergoes molecular and cellular changes, accumulates macrophages, and secretes various immune factors such as inflammatory cytokines [101, 102]. These cytokines subsequently suppress feeding and induce energy expenditure, similar to the anorexigenic effects observed within the APR, via a feedback loop to prevent excessive fat accumulation (i.e. obesity), and thus, maintain homeostatic balance [103]. Once caloric restriction is achieved, it is accompanied by a potent anti-inflammatory effect which can include reduced production of inflammatory cytokines and prostaglandins, lowered blood lymphocyte counts, and reduced macrophage activation and infiltration into adipocytes (fig. 2) [102, 104, 105]. 
Fig. 2. Cytokine involvement in adiposity signalling. The adiposity signalling pathway of inflammatory cytokines is shown. Cytokines, which are elevated during fat accumulation, act within the hypothalamus to initiate anorexigenic pathways, to ultimately decrease food intake and increase energy expenditure. Once caloric restriction is achieved, cytokine levels are reduced. Antipsychotics may perturb adiposity signalling by reducing central cytokine levels, thereby blocking the illustrated pathway at the level of the hypothalamus, and shifting weight outcomes back toward fat accumulation.

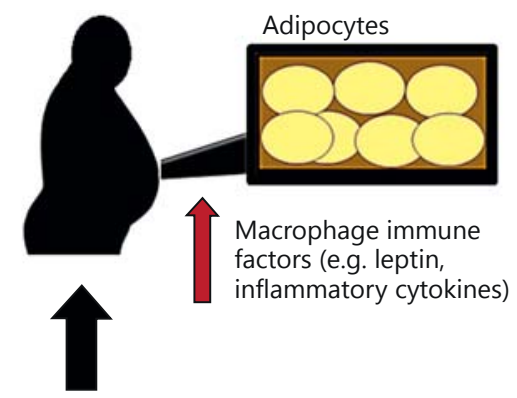

Pro-inflammatory cytokines Prostaglandins Blood lymphocyte counts Macrophage activation

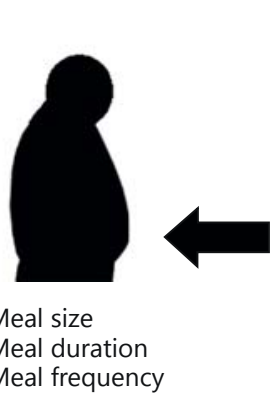

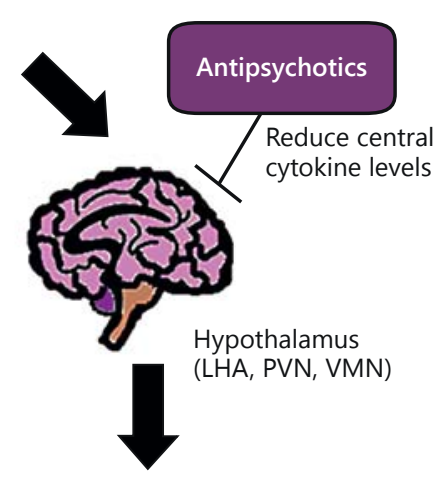

Anorexigenic signalling pathways (e.g. NPY, AgRP, ghrelin, POMC, CART, monoamines)

\section{Central and Peripheral Mechanisms of Cytokine-}

Induced Anorexia

Peripheral cytokines can stimulate the vagus nerve of the abdomen and gastrointestinal tract which relay signals to the hypothalamus [15]. The vagus nerve may partially mediate anorexigenic effects, as sub-diaphragmatic vagotomy can attenuate suppression of food intake [106] and food-motivated behaviour [106], but not in all cases [107]. Cytokines may work with the peripheral satiety hormone, cholecystokinin (CCK), to stimulate the vagus nerve, as cytokine-induced release of CCK and activation of $\mathrm{CCK}_{\mathrm{A}}$ receptors partially contribute to vagal-mediated hypophagic outcomes [72]. In addition, cytokines like IL- 1 and TNF- $\alpha$ act directly on adipocytes to stimulate leptin secretion to suppress food intake [108-112], and influence levels of insulin and glucagon [113]. Further, IL-1, IL-6, and TNF- $\alpha$ reduce stomach muscle contractions to yield gastric stasis (i.e. delayed gastric emptying) which contributes to anorexia by influencing meal size and length of inter-meal intervals [114]. The involvement of inflammatory cytokines within multiple metabolic pathways in the periphery provides some insight into the importance of these adiposity signals in the regulation of energy homeostasis.

In the CNS, cytokines have direct action at hypothalamic neurons in the LHA, PVN, and VMN in mediating feeding behaviours [113]. In support, cytokine mRNA and protein, and cytokine receptors have been found in multiple brain regions including the hypothalamus [115117], with greatest concentrations in the VMH [69]. In anorexic tumour-bearing rats, IL- $1 \beta$ and IL-1R mRNA are up-regulated in the hypothalamus, and cerebrospinal fluid levels of IL-1 negatively correlate with food intake [69]. Kent et al. [118] demonstrated that direct administration of recombinant IL- $1 \beta$ into the VMN both timeand dose-dependently induced anorexia and weight loss, with food and water consumption reduced by 45 and $30 \%$, respectively. VMN-injected cytokine antagonists can also reverse anorexic outcomes by improving food intake $[119,120]$. These data provide further support for the direct involvement of cytokines in the hypothalamic regulation of metabolic activity.

Cytokines can also mediate anorexigenic effects by influencing hypothalamic production of various neurotransmitters and neuropeptides that are relevant to the regulation of food intake. For example, central cytokine administration can reduce levels of NPY, an important orexigenic factor [121]. Sonti et al. [122] observed that NPY administration blocks the anorexic effects of IL- $1 \beta$ and induces feeding in anorexic rats. A similar relationship exists between NPY and interferon- $\alpha$ [82]. Lipopolysaccharide endotoxin and IL- $1 \beta$ have been shown to decrease plasma levels of the orexigenic factor, ghrelin, an effect which can be blocked by administration of exoge- 
nous ghrelin, IL-1RA, and the non-steroidal anti-inflammatory drug, indomethacin [123]. In other words, administration of anti-inflammatory factors restores orexigenic signalling in cases where cytokine levels are elevated. Cytokines also interact with other neuropeptides (e.g. POMC-derived peptides, hypocretins/orexins, CART, melanin-concentrating hormone, and AgRP) and neurotransmitters (e.g. dopamine, serotonin, histamine, and norepinephrine) which are involved in regulating food intake [113, 117, 124]. Cytokines are extensively integrated into the hypothalamic metabolic circuit, both regulating and being regulated by various neurotransmitters and neuropeptides, which emphasizes their importance within energy homeostatic pathways.

In addition, secondary cytokine messengers such as prostaglandins, especially prostaglandin $\mathrm{E}_{2}$, and their precursors have been shown to reduce food intake and influence gastrointestinal motility [125-130]. These anorexigenic effects are typically reversible by COX inhibitors like aspirin, flurbiprofen, indomethacin, and paracetamol, which possess anti-inflammatory properties $[125,127]$. In support, pre-treatment with COX inhibitors can partially block the anorexic and gastric emptying effects of IL-1 and TNF [114]. Furthermore, cytokines activate the hypothalamic-pituitary-adrenal (HPA) axis $[131,132]$, and simulate release of corticotropin-releasing hormone (CRH) [133-136] which acts within the brain to reduce food intake [137]. Uehara et al. [138] demonstrated that pre-treatment with $\mathrm{CRH}$-antiserum blocks reductions in food intake subsequent to IL- $1 \beta$ administration. Overall, the involvement of cytokines in the regulation of feeding behaviours appears to be non-linear and highly extensive involving interactions with various regulatory factors and multiple pathway redundancies.

\section{Disruption of Cytokine Signalling in Normal Weight Regulation and Its Implications for Obesity}

\section{Obesity as a Consequence of Cytokine Function Disruption}

Any perturbations to cytokine-mediated adiposity signalling may cause a shift in weight outcomes. In cases where weight gain is specifically concerned, this outcome may theoretically occur in one of two ways: (1) a developed resistance to inflammatory signalling despite an intact ability to up-regulate cytokine expression, or (2) a blunted ability to up-regulate cytokine expression when needed. In either situation, important information on adiposity reserves fails to be conveyed to the hypothalamus which precludes the initiation of anorexigenic responses, leading to continued fat accumulation, and ultimately, obesity [103]. A recent review by Wang and Ye [139] highlights the critical role of inflammation in the maintenance of energy homeostasis, commenting on how a lack of responsiveness to inflammatory cytokines will skew metabolic outcomes toward obesity while elevated inflammatory activity leads to weight loss and malnutrition, as observed in cancer cachexia.

Inflammatory resistance is observable within general obesity (and metabolic syndrome), where low-grade inflammation is chronically present but with no accompanying reduction in weight [140]. In further support, hyperglycaemia and type 2 diabetes mellitus, which are by-products of obesity-induced/inflammation-induced (particularly via increased levels of TNF- $\alpha$ and IL-6) insulin resistance, are characterized by glucose excretion in the urine, which may be an extreme method to rid the body of surplus energy where more traditional homeostatic mechanisms have failed [103, 141]. Moreover, weight loss in morbidly obese patients yields an improvement in insulin resistance when accompanied by significant reductions in C-reactive protein (CRP) and IL-6 [142].

Similar to inflammatory resistance, a deficit of inflammatory signalling in the face of increased adiposity would yield comparable obesity outcomes. In support, O’Rourke et al. [143] found decreased serum cytokine protein and mRNA levels in peripheral blood mononuclear cells of obese compared to lean patients, which occurred in spite of an intact capacity to up-regulate cytokine expression in response to leptin. These data suggest that obesity may result from reduced inflammatory signalling and/or responsiveness to inflammatory cytokines, which would consequently limit anorexigenic outcomes and weight regulation.

\section{Genetic Knockout Models of Cytokine-Induced Obesity}

Various models have tested the association between deficit cytokine production and obesity outcomes using genetic knockout models. Wallenius et al. [19] observed that IL-6-deficient mice (IL-6 ${ }^{-/}$) developed mature-onset obesity accompanied by increased food intake, altered carbohydrate and lipid metabolism, increased leptin levels, and reduced responsiveness to leptin treatment. IL-6 administration was able to partially reverse these effects by lowering body weight and leptin levels, and increasing energy expenditure. However, other research has shown no significant differences between IL- $6^{-/-}$and wild-type 
mice on measures of obesity, fasting hyperglycaemia or lipid metabolism [144]. Investigations of IL-1 involvement have yielded similar findings. Garcia et al. [145] found that mice with an IL-1R deficiency (IL-1RI ${ }^{-/-}$) developed mature-onset obesity relative to wild-type mice by 5 to 6 months of age, with a 20\% weight difference emerging by 9 months. IL-1RI ${ }^{-/-}$mice also developed a 1.5- to 2.5-fold increase in visceral and subcutaneous fat mass, insulin resistance, increased leptin levels and, prior to obesity onset, lower locomotor activity and reduced suppression of body weight and food intake in response to leptin. These developmental data suggest that cytokines exert extensive metabolic effects from relatively early on in life.

Furthermore, McGillicuddy et al. [146] noted that IL$1 \mathrm{RI}^{-/-}$mice developed mature-onset obesity after 6 months despite being fed a low-fat diet, thereby suggesting that obesity outcomes are primarily regulated by internal factors and can occur independent of the environment. Finally, Netea et al. [147] showed that deficiency of IL-18 (IL-18 ${ }^{-/-}$) in mice led to higher leptin levels, hyperphagia, increased cholesterol and triglyceride concentrations, obesity, and insulin resistance, which could all be partly reversed with central administration of recombinant IL-18. Obesity differences, relative to control mice, first appeared at 6 months of age, with the greatest difference of $38.1 \%$ occurring at 12 months. Mice deficient for the IL-18R (IL-18R $\mathrm{R}^{-/-}$) also displayed similar obesity and insulin resistance outcomes. Overall, these data suggest that the role of cytokines within metabolic regulation is not limited to food intake and weight outcomes, but rather, includes more global effects on various metabolic parameters. These findings may provide additional insights into the host of metabolic consequences that often occur in tandem with AIWG among AP-treated patients.

There is also an observed synergy between cytokines in yielding weight change effects. Chida et al. [18] found that mice with a combined IL- 1 and IL- 6 deficiency (IL$\left.1^{-/-} / \mathrm{IL}-6^{-/-}\right)$developed obesity by 10 weeks while mice with either an IL-1 or IL- 6 knockout remained normal at this age. IL-1 $1^{-/} / \mathrm{IL}-6^{-/-}$mice also had significantly higher daily food intake and greater suppression of anorexic effects after peripheral IL-1 administration. These results provide further support for the redundancies in cytokine metabolic pathways, as functional blockade of one cytokine pathway does not necessarily lead to global orexigenic effects.

In addition to inflammatory cytokines, anti-inflammatory factors can also yield considerable, yet opposing effects on weight change outcomes. IL-1RA ${ }^{-/-}$mice, in

Cytokines in Antipsychotic-Induced

Weight Gain which excess IL-1 signalling may occur, have a lean phenotype through impaired body fat accumulation and lipid storage, and resistance against the obesity-inducing effects of both monosodium glutamate and a high-fat diet [148]. Additional studies of IL-1RA ${ }^{-1-}$ mice revealed a lean phenotype based on reduced fat mass, dysfunctional adipogenesis, and increased energy expenditure, in addition to reduced body weight relative to heterozygote IL$1 \mathrm{RA}^{+/-}$littermates $[149,150]$. Thus, anti-inflammatory cytokines appear to work in concert with inflammatory cytokines to indirectly regulate homeostatic balance through their antagonizing effects on pro-inflammatory activity.

\section{Cytokine Genetic Variants and Obesity}

Genetic investigations involving polymorphisms in cytokine genes show an association with obesity in humans. Andersson et al. [151] found that the $3^{\prime}$ untranslated region variant rs4252041 (C>T) of the IL-1RA gene was associated with lower total and regional fat mass, total fat percent (\%) and body mass index (BMI) in men. Um et al. [152] found two IL-1 a polymorphisms, C-889T (rs 1800587) and G+4845T (rs17561), that were associated with an increase in BMI in obese healthy women. Lee et al. [153] investigated the IL-1 $\beta+3953$ (rs1 143634) variant site, finding a higher frequency of the $\mathrm{T}(\mathrm{CT} / \mathrm{TT})$, or high transcriptional, allele among lean BMI $(<25)$ versus overweight BMI (25-29) females. The same locus was tested by Manica-Cattani et al. [21], similarly finding a higher $\mathrm{T}$ allele frequency in non-overweight than overweight and obese groups. Strandberg et al. [154] also tested the +3953 variant but against body fat mass in men Results showed that carriers of the $\mathrm{T}$ allele had significantly lower total fat mass, in addition to reduced arm, leg, and trunk fat.

The IL- 6 gene has also been implicated in metabolic outcomes. Additional investigations by Strandberg et al. [155] found an association for both the IL- $1 \beta-31 \mathrm{~T}>\mathrm{C}(\mathrm{rs} 1143627)$ and IL-6 -174 G>C (rs1800795) polymorphisms with total and regional fat mass in elderly men. Interestingly, the IL-6 $-174 \mathrm{C}$ variant, which produces less IL-6, has been associated with higher BMI and risk of obesity-related metabolic indices like insulin resistance and high systolic blood pressure $[156,157]$, while the $-174 \mathrm{G}$ variant has been associated with a lean phenotype, low waist circumference, and low concentrations of insulin or glucose [22]. Andersson et al. [158] found the IL-6 rs $10242595^{*}$ A variant to be associated with low BMI and total body fat mass, and smaller regional fat masses. In addition, the IL-6 promoter polymorphism, rs2069827 G>T, is associated with elevated early- 
adulthood BMI, baseline BMI, and waist circumference in men and women, separately [159]. Wolford et al. [160] studied multiple polymorphisms across the IL-6R gene (rs4845623 T>C, c_1981308_10 T>C, rs2228145 T>G, c_1158918_10 G>C, rs2229328 T>C) finding that carriers of the variant allele for these sites had a higher mean BMI compared to those with the wild-type allele when tested among non-diabetic Pima Indians.

In addition to research examining general obesity outcomes, previous investigations by our own study team have identified multiple cytokine polymorphisms associated with AIWG. We found that variant sites across the IL-1 $\beta$ gene, specifically rs $16944^{*} \mathrm{GA}, \mathrm{rs} 1143634^{*} \mathrm{G}$, and rs4849127*A, were associated with greater AIWG in schizophrenia patients [161]. Our analyses further identified epistatic effects between IL-1 $\beta$ (rs13032029, rs16944) and the anorexigenic neurotrophin, brain-derived neurotrophic factor (BDNF), specifically the Val66Met variant, in predicting AIWG outcomes. Epistatic interactions were also demonstrated between IL-6 rs2069837 and BDNF Val66Met [161]. Furthermore, an expansion of GWAS results from the Genetic Investigation of ANthropometric Traits (GIANT) identified associations between $\mathrm{BMI}$ and variants across genes associated with the MAPK pathway, which has been implicated in cytokine signalling [162]. Despite the availability of genetic data, interpretation of these results is limited by the absence of functional data which are needed to determine the direction of association. Nevertheless, these results, which highlight the significant influence of genetic variability across cytokine genes on weight gain outcomes, suggest that AIWG may partially derive from a genetic susceptibility.

\section{Antipsychotic-Induced Disruption of Cytokine Signalling and the AIWG Side Effect}

\section{Linking the Anti-Inflammatory Properties of Antipsychotics to AIWG}

Several studies suggest that APs have immunomodulatory properties (table 1), particularly anti-inflammatory effects, which may contribute to their clinical efficacy. Long-term treatment with APs has primarily been shown to increase expression of anti-inflammatory mediators (e.g. sIL-1RA, sIL-2R, and IL-10) while simultaneously reducing pro-inflammatory markers (e.g. IL- $1 \beta$, IL-2, IL6 , sIL-6R, and TNF- $\alpha$ ) in the periphery and CNS $[17,27$, 163]. Despite these main trends, a meta-analysis of cytokine alterations in schizophrenia patients proposed that only state marker cytokines such as IL-1 $\beta$ and IL-6 are
Table 1. Immune alterations through antipsychotic treatment

\begin{tabular}{lll}
\hline Immune biomarker & $\begin{array}{l}\text { Primary direc- Citations } \\
\text { tion of change }\end{array}$ \\
\hline $\begin{array}{l}\text { Inflammatory cytokines }{ }^{\text {a }} \text { (e.g. IL-1, } \\
\quad \text { IL-2, IL-6, IL-6R, TNF- } \alpha\end{array}$ & $\downarrow$ & $17,27,163$ \\
$\begin{array}{l}\text { Anti-inflammatory cytokines } \\
\quad(\text { e.g. sIL-1RA, sIL-2R, IL-10) }\end{array}$ & $\uparrow$ & $17,27,163$ \\
S100B & $\uparrow$ & 168,169 \\
Microglia activation & $\downarrow$ & 165,166 \\
Nitric oxide release & $\downarrow$ & 165,166 \\
ROS & $\downarrow$ & 167 \\
\hline
\end{tabular}

${ }^{\text {a }}$ In both the periphery and CNS.

responsive to AP treatment, while trait makers such as interferon- $\gamma$, TNF- $\alpha$, and sIL-2R, remain unchanged [164]. The reverse relationship has also been demonstrated with levels of inflammatory cytokines increasing subsequent to AP treatment [16]. However, these results should be cautiously interpreted as the use of serological methodology can compromise data outcomes through the introduction of various confounds which can alter peripheral cytokine expression. APs have also been shown to reduce microglia activation and release of nitric oxide and ROS [165-167], and increase levels of S100B (a calcium- and zinc-binding protein which serves as a marker for astrocyte activity) in some $[168,169]$ but not all cases [170]. Additional support for the anti-inflammatory properties of APs is derived from reports of AP efficacy in treating inflammation-based conditions such as tuberculosis/mycobacterial infections [171], and rheumatoid arthritis [172]. APs may mediate these effects by suppressing production of pro-inflammatory cytokines and nitric oxide from activated microglia $[31,34]$.

The alteration of cytokine systems by APs may have secondary consequences on normal adiposity signalling by disrupting inflammatory cytokine release. If levels of inflammatory cytokines are suppressed, information on long-term energy stores may be compromised, thereby preventing hypothalamic circuits from restoring energy homeostasis via anorexigenic responses. This may ultimately lead to a continued accumulation of adiposity demonstrated as weight gain and/or obesity (fig. 2). Moreover, SGAs have more potent anti-inflammatory properties relative to FGAs $[27,173]$, which provides support for data trends which consistently implicate SGAs in having a greater propensity toward AIWG as compared to FGA treatments. 
Preliminary Evidence Supporting a Cytokine-

Mediated Model of AIWG

There is a growing body of evidence that supports the role of cytokine dysfunction in metabolic disturbances, like AIWG, in schizophrenia. A recent genetic analysis by Chase et al. [174] identified concurrent dysregulation of obesogenic (e.g. peroxisome proliferator-activated receptor, sterol regulatory element binding transcription factor 1) and immunogenetic (e.g. IL-6, TNF- $\alpha$, CCAAT/enhancer-binding protein- $\alpha$ ) gene expression in schizophrenia patients. An additional analysis of blood mononuclear cells further identified a significant difference between obese and non-obese schizophrenia patients on measures of inflammatory cytokines, in addition to serum levels of leptin and adiponectin [175].

In considering the proposed immunomodulatory properties of APs, it is plausible that immune factors contribute to AIWG. This theory has received some attention in recent years, starting with Klunge et al. [176] who proposed that the effects of clozapine and olanzapine on weight gain may be closely related to their effects on cytokine networks. In this study, 30 patients diagnosed with schizophrenia, schizophreniform or schizoaffective disorder were randomized to either clozapine (mean modal dose: $266.7 \pm 77.9 \mathrm{mg})$ or olanzapine $(21.2 \pm 2.5 \mathrm{mg})$ treatment for 6 weeks. Data were longitudinally collected on BMI, and plasma levels of leptin and cytokines which included TNF- $\alpha$, soluble TNF receptor (sTNFR)-1, sTNFR-2, IL-6, and sIL-2R. All cytokine levels were found to significantly change over time, with the exception of IL-6 and sTNFR-1 among olanzapine-treated patients, thereby suggesting treatment-specific effects on cytokine systems. In addition, TNF- $\alpha$, sTNFR-1, sTNFR-2, and sIL-2R levels correlated with BMI after 6 weeks of treatment.

Similarly, Song et al. [177] observed significant alterations in serum levels of IL- $1 \beta$, IL- 6 , and TNF- $\alpha$, in addition to body weight, over 6 months of risperidone treatment in 62 drug-naïve first-episode schizophrenia patients. In fact, patients who experienced clinically significant $(>7 \%)$ weight gain by the end of treatment had higher levels of all cytokine markers compared to patients who gained $<7 \%$ of weight. However, the data from these last two studies are limited by their relatively small sample sizes. Therefore, additional cytokine analyses in larger clinical samples are required to more clearly elucidate the cytokine-AIWG relationship.

Klemettila et al. [178] relied on a larger sample of 190 treatment-resistant schizophrenia patients who were administered clozapine. Results showed that levels of IL-

Cytokines in Antipsychotic-Induced

Weight Gain
1RA and CRP were associated with obesity after controlling for age and smoking status, as was IL-6 specifically among female patients. Together, these data suggest both age- and gender-dependent cytokine effects which show that the cytokine-AIWG relationship can be affected by patient-related variables. Overall, these results indicate that administration of AP treatment yields alterations of cytokine levels which occur in tandem with changes to weight outcomes. Thus, these findings provide preliminary support for a cytokine-mediated immune model of AIWG.

\section{Conclusions}

At this time, preliminary evidence suggests that the immune system may partially contribute to AIWG via APmediated alterations of cytokine levels. Antipsychotics with a high propensity for weight gain likely yield these effects through their documented ability to decrease proinflammatory cytokine production while increasing levels of anti-inflammatory mediators to ultimately down-regulate neuroinflammation. In considering that anorexigenic outcomes are mediated via increased levels of inflammatory cytokines, these AP-induced alterations create an internal inflammatory milieu which may disrupt adiposity signalling in favour of fat accumulation. As documented within this review, obesity outcomes are associated with a reduced production and/or responsiveness to inflammatory cytokines. Hence, reduced inflammatory cytokine signalling resulting from AP administration has the potential to yield AIWG, as further supported by serological data in AP-treated schizophrenia patients. Based on the available literature, the inflammatory cytokines IL-1, IL-6, and TNF- $\alpha$ may be particularly key players in mediating the relationship between APs and AIWG.

Based on this hypothesized model, it may be advisable for clinicians to routinely monitor patients for changes in blood levels of inflammatory mediators, particularly IL-1, IL- 6 , and TNF- $\alpha$, in addition to completing standard metabolic profiling. However, clinical monitoring of peripheral cytokine levels remains, at this preliminary stage, only a potential screening tool that would require further research to enhance its clinical application, particularly by addressing the issues of situational confounds of serological methodology, identifying a plasma level range for healthy versus pathological plasma cytokine concentrations, and generating clinical guidelines on how to interpret blood reports. This information may also inform new cytokine drug targets for AIWG in AP-treated popula- 
tions. However, in considering that reduced neuroinflammation may mediate therapeutic response to APs, such a targeted approach to improving AIWG will need to be balanced against secondary effects on clinical efficacy. Cytokine data may also have clinical application in designing predictive biomarker screens for AIWG which may include serological quantification of circulating cytokines in the blood or cerebrospinal fluid, or high-throughput genetic analyses of cytokine polymorphisms. However, since details characterizing the relationship between cytokines and AIWG have yet to be clearly elucidated, further research is required before more effective clinical guidelines and prevention measures can be developed.

\section{Acknowledgements}

T.M.F. is a recipient of a Canadian Institutes of Health Research (CIHR) 2012 Frederick Banting and Charles Best Masters Award. S.H.K. has received grant/research support from Ontario
Brain Institute, Brain Canada and CIHR. D.J.M. has received the following: CIHR operating grant (Genetics of Antipsychotics Induced Metabolic Syndrome, MOP 89853), Brain \& Behaviour Research Foundation NARSAD Independent Investigator Award, CIHR Michael Smith New Investigator Salary Prize for Research in Schizophrenia, Early Researcher Award from the Ontario Ministry of Research and Innovation, and a New Investigator Fellowship from the Ontario Mental Health Foundation (OMHF). The content of this paper is solely the responsibility of the authors and does not necessarily represent the official views of these organizations.

\section{Disclosure Statement}

We confirm this paper describes original work that has not been published elsewhere and is not under consideration by another journal. S.H.K. has received research support from Lundbeck, St. Jude Medical, Bristol-Myers Squibb, and Clera Inc. He has received speaking fees from and/or is a member of an advisory board for Eli Lilly, Janssen Inc., Lundbeck, Lundbeck Institute, Pfizer, Bristol Myers Squibb, and Servier.

\section{References}

1 De Hert M, Correll CU, Bobes J, CetkovichBakmas M, Cohen D, Asai I, Detraux J, Gautam S, Möller HJ, Ndetei DM, Newcomer JW, Uwakwe R, Leucht S: Physical illness in patients with severe mental disorders. I. Prevalence, impact of medications and disparities in health care. World Psychiatry 2011;10:5277.

2 Editorial: drugs causing weight gain. BMJ 1974;1:168.

3 Planansky K: Changes in weight in patients receiving a tranquilizing drug. Psychiatr Q 1958;32:289-303.

4 Lett TA, Wallace TJ, Chowdhury NI, Tiwari AK, Kennedy JL, Müller DJ: Pharmacogenetics of antipsychotic-induced weight gain: review and clinical implications. Mol Psychiatry 2012;17:242-266.

5 Allison DB, Mentore JL, Heo M, Chandler LP, Cappelleri JC, Infante MC, Weiden PJ: Antipsychotic-induced weight gain: a comprehensive research synthesis. Am J Psychiatry 1999; 156:1686-1696.

6 Bak M, Fransen A, Janssen J, van Os J, Drukker M: Almost all antipsychotics result in weight gain: a meta-analysis. PLoS One 2014; 9:e94112.

7 De Hert M, Detraux J, van Winkel R, Yu W, Correll CU: Metabolic and cardiovascular adverse effects associated with antipsychotic drugs. Nat Rev Endocrinol 2012;8:114-126.

8 Bernstein JG: Induction of obesity by psychotropic drugs. Ann NY Acad Sci 1987;499:203215.
9 Zhang ZJ, Yao ZJ, Liu W, Fang Q, Reynolds GP: Effects of antipsychotics on fat deposition and changes in leptin and insulin levels. Magnetic resonance imaging study of previously untreated people with schizophrenia. Br J Psychiatry 2004;184:58-62.

10 Mitchell AJ, Vancampfort D, De Herdt A, Yu W, De Hert M: Is the prevalence of metabolic syndrome and metabolic abnormalities increased in early schizophrenia? A comparative meta-analysis of first episode, untreated and treated patients. Schizophr Bull 2013;39: 295-305.

11 McIntyre RS, Mancini DA, Basile VS, Srinivasan J, Kennedy SH: Antipsychotic-induced weight gain: bipolar disorder and leptin. J Clin Psychopharmacol 2003;23:323-327.

12 Chen J, Gao K, Kemp DE: Second-generation antipsychotics in major depressive disorder: update and clinical perspective. Curr Opin Psychiatry 2011;24:10-17.

13 Hellings JA, Zarcone JR, Crandall K, Wallace $\mathrm{D}$, Schroeder SR: Weight gain in a controlled study of risperidone in children, adolescents and adults with mental retardation and autism. J Child Adolesc Psychopharmacol 2001; 11:229-238

14 Ondo WG, Jong D, Davis A: Comparison of weight gain in treatments for Tourette syndrome: tetrabenazine versus neuroleptic drugs. J Child Neurol 2008;23:435-437.

15 Wysokinski A, Kloszewska I: Mechanisms of increased appetite and weight gain induced by psychotropic medications. J Adv Clin Pharmacol 2014;1:12-33.
16 Pollmacher T, Haack M, Schuld A, Kraus T, Hinze-Selch D: Effects of antipsychotic drugs on cytokine networks. J Psychiatr Res 2000; 34:369-382.

17 Drzyzga L, Obuchowicz E, Marcinowska A, Herman ZS: Cytokines in schizophrenia and the effects of antipsychotic drugs. Brain Behav Immun 2006;20:532-545.

18 Chida D, Osaka T, Hashimoto O, Iwakura Y: Combined interleukin- 6 and interleukin-1 deficiency causes obesity in young mice. Diabetes 2006;55:971-977.

19 Wallenius V, Wallenius K, Ahren B, Rudling M, Carlsten H, Dickson SL, Ohlsson C, Jansson JO: Interleukin-6-deficient mice develop mature-onset obesity. Nat Med 2002;8:75-79.

20 Finck BN, Johnson RW: Anorexia, weight loss and increased plasma interleukin- 6 caused by chronic intracerebroventricular infusion of interleukin-1beta in the rat. Brain Res 1997; 761:333-337.

21 Manica-Cattani MF, Bittencourt L, Rocha MI, Algarve TD, Bodanese LC, Rech R, Machado MM, Santos GF, Gottlieb MG, Schwanke CH, Piccoli JE, Duarte MF, Cruz IB: Association between interleukin-1 beta polymorphism (+3953) and obesity. Mol Cell Endocrinol 2010;314:84-89.

22 Berthier MT, Paradis AM, Tchernof A, Bergeron J, Prud'homme D, Després JP, Vohl MC: The interleukin 6-174G/C polymorphism is associated with indices of obesity in men. J Hum Genet 2003;48:14-19. 
23 Thorleifsson G, Walters GB, Gudbjartsson DF, Steinthorsdottir V, et al: Genome-wide association yields new sequence variants at seven loci that associate with measures of obesity. Nat Genet 2009;41:18-24.

24 Wang YC, Bai YM, Chen JY, Lin CC, Lai IC, Liou YJ: Genetic association between TNFalpha $-308 \mathrm{G}>\mathrm{A}$ polymorphism and longitudinal weight change during clozapine treatment. Hum Psychopharmacol 2010;25:303309.

25 Dinarello CA: Role of pro- and anti-inflammatory cytokines during inflammation: experimental and clinical findings. J Biol Regul Homeost Agents 1997;11:91-103.

26 Potvin S, Stip E, Sepehry AA, Gendron A, Bah $\mathrm{R}$, Kouassi E: Inflammatory cytokine alterations in schizophrenia: a systematic quantitative review. Biol Psychiatry 2008;63:801-808.

27 Meyer U, Schwarz MJ, Muller N: Inflammatory processes in schizophrenia: a promising neuroimmunological target for the treatment of negative/cognitive symptoms and beyond. Pharmacol Ther 2011;132:96-110.

28 Beumer W, Gibney SM, Drexhage RC, PontLezica L, Doorduin J, Klein HC, Steiner J, Connor TJ, Harkin A, Versnel MA, Drexhage HA: The immune theory of psychiatric diseases: a key role for activated microglia and circulating monocytes. J Leukoc Biol 2012;92: 959-975.

29 Ishii KJ, Koyama S, Nakagawa A, Coban C, Akira S: Host innate immune receptors and beyond: making sense of microbial infections. Cell Host Microbe 2008;3:352-363.

30 Alberts B, Johnson A, Lewis J, Raff M, Roberts K, Walter P: Molecular Biology of the Cell, ed 4. New York, Garland Science, 2002.

$31 \mathrm{Na}$ KS, Jung HY, Kim YK: The role of proinflammatory cytokines in the neuroinflammation and neurogenesis of schizophrenia. Prog Neuropsychopharmacol Biol Psychiatry 2014;48:277-286.

32 Barton GM: A calculated response: control of inflammation by the innate immune system. J Clin Invest 2008;118:413-420.

33 Ransohoff RM, Brown MA: Innate immunity in the central nervous system. J Clin Invest 2012;122:1164-1171

34 Monji A, Kato T, Kanba S: Cytokines and schizophrenia: microglia hypothesis of schizophrenia. Psychiatry Clin Neurosci 2009;63:257-265.

35 Kreutzberg GW: Microglia: a sensor for pathological events in the CNS. Trends Neurosci 1996;19:312-318.

36 Banati RB, Gehrmann J, Schubert P, Kreutzberg GW: Cytotoxicity of microglia. Glia 1993;7:111-118.

37 Bergink V, Gibney SM, Drexhage HA: Autoimmunity, inflammation, and psychosis: a search for peripheral markers. Biol Psychiatry 2014;75:324-331.

38 Najjar S, Pearlman DM, Alper K, Najjar A, Devinsky O: Neuroinflammation and psychiatric illness. J Neuroinflammation 2013;10: 43.
39 Dong Y, Benveniste EN: Immune function of astrocytes. Glia 2001;36:180-190.

40 Banks WA: Blood-brain barrier transport of cytokines: a mechanism for neuropathology. Curr Pharm Des 2005;11:973-984.

41 Quan N, Whiteside M, Herkenham M: Time course and localization patterns of interleukin-1beta messenger RNA expression in brain and pituitary after peripheral administration of lipopolysaccharide. Neuroscience 1998;83:281-293.

42 Roth J, Harre EM, Rummel C, Gerstberger R, Hübschle T: Signaling the brain in systemic inflammation: role of sensory circumventricular organs. Front Biosci 2004;9:290-300.

43 Johnson AK, Gross PM: Sensory circumventricular organs and brain homeostatic pathways. FASEB J 1993;7:678-686.

44 Plotkin SR, Banks WA, Kastin AJ: Comparison of saturable transport and extracellular pathways in the passage of interleukin- 1 alpha across the blood-brain barrier. J Neuroimmunol 1996;67:41-47.

45 Quan N, Banks WA: Brain-immune communication pathways. Brain Behav Immun 2007; 21:727-735.

46 Verma S, Nakaoke R, Dohgu S, Banks WA Release of cytokines by brain endothelial cells: a polarized response to lipopolysaccharide. Brain Behav Immun 2006;20:449-455.

47 Fabry Z, Fitzsimmons KM, Herlein JA, Moninger TO, Dobbs MB, Hart MN: Production of the cytokines interleukin 1 and 6 by murine brain microvessel endothelium and smooth muscle pericytes. J Neuroimmunol 1993;47: 23-34.

48 Konsman JP, Parnet P, Dantzer R: Cytokineinduced sickness behaviour: mechanisms and implications. Trends Neurosci 2002;25:154159.

49 Wang X, Wang BR, Zhang XJ, Xu Z, Ding YQ, Ju G: Evidences for vagus nerve in maintenance of immune balance and transmission of immune information from gut to brain in STM-infected rats. World J Gastroenterol 2002;8:540-545.

50 Dantzer R, Konsman JP, Bluthe RM, Kelley KW: Neural and humoral pathways of communication from the immune system to the brain: parallel or convergent? Auton Neurosci 2000;85:60-65.

51 Goehler LE, Gaykema RP, Hansen MK, Anderson K, Maier SF, Watkins LR: Vagal immune-to-brain communication: a visceral chemosensory pathway. Auton Neurosci 2000;85:49-59.

52 Dantzer R, O'Connor JC, Freund GG, Johnson RW, Kelley KW: From inflammation to sickness and depression: when the immune system subjugates the brain. Nat Rev Neurosci 2008;9:46-56.

53 Waldmann TA: The biology of interleukin-2 and interleukin-15: implications for cancer therapy and vaccine design. Nat Rev Immunol 2006;6:595-601.
54 Meyer U: Anti-inflammatory signaling in schizophrenia. Brain Behav Immun 2011;25: 1507-1518.

55 Keller ET, Wanagat J, Ershler WB: Molecular and cellular biology of interleukin- 6 and its receptor. Front Biosci 1996;1:d340-d357.

56 Contassot E, Beer HD, French LE: Interleukin-1, inflammasomes, autoinflammation and the skin. Swiss Med Wkly 2012;142: w13590.

57 Weber A, Wasiliew P, Kracht M: Interleukin-1 (IL-1) pathway. Sci Signal 2010;3: cm1.

58 Janssen DG, Caniato RN, Verster JC, Baune BT: A psychoneuroimmunological review on cytokines involved in antidepressant treatment response. Hum Psychopharmacol 2010; 25:201-215.

59 Coccurello R, Moles A: Potential mechanisms of atypical antipsychotic-induced metabolic derangement: clues for understanding obesity and novel drug design. Pharmacol Ther 2010; 127:210-51.

60 Correll CU, Lencz T, Malhotra AK: Antipsychotic drugs and obesity. Trends Mol Med 2011;17:97-107.

61 Schwartz MW, Baskin DG, Kaiyala KJ, Woods SC: Model for the regulation of energy balance and adiposity by the central nervous system. Am J Clin Nutr 1999;69:584-596.

62 Leibowitz SF, Wortley KE: Hypothalamic control of energy balance: different peptides, different functions. Peptides 2004;25:473504.

63 Wilding JP: Neuropeptides and appetite control. Diabet Med 2002;19:619-627.

64 Lenard NR, Berthoud HR: Central and peripheral regulation of food intake and physical activity: pathways and genes. Obesity (Silver Spring) 2008;16(suppl 3):S11-S22.

65 Connor TJ, Song C, Leonard BE, Merali Z, Anisman H: An assessment of the effects of central interleukin-1beta, $-2,-6$, and tumor necrosis factor-alpha administration on some behavioural, neurochemical, endocrine and immune parameters in the rat. Neuroscience 1998;84:923-933.

66 Szelenyi J: Cytokines and the central nervous system. Brain Res Bull 2001;54:329-338.

67 Grill HJ: Distributed neural control of energy balance: contributions from hindbrain and hypothalamus. Obesity (Silver Spring) 2006; 14(suppl 5):216S-221S.

68 Berthoud HR: Mind versus metabolism in the control of food intake and energy balance. Physiol Behav 2004;81:781-793.

69 Guijarro A, Laviano A, Meguid MM: Hypothalamic integration of immune function and metabolism. Prog Brain Res 2006;153:367-405.

70 Johnson RW: Immune and endocrine regulation of food intake in sick animals. Domest Anim Endocrinol 1998;15:309-319.

71 Kushner I: Regulation of the acute phase response by cytokines; in Oppenheim JJ, Rossio J, Gearing AJH (eds): Clinical Applications of Cytokines: Role in Pathogenesis, Diagnosis, and Therapy. New York, Oxford University Press, 1993. 
72 Langhans W: Anorexia of infection: current prospects. Nutrition 2000;16:996-1005.

73 Exton MS: Infection-induced anorexia: active host defence strategy. Appetite 1997;29:369383.

74 Gabay C, Kushner I: Acute-phase proteins and other systemic responses to inflammation. N Engl J Med 1999;340:448-454.

75 Kanra GY, Ozen H, Kara A: Infection and anorexia. Turk J Pediatr 2006;48:279-287.

76 Murray MJ, Murray AB: Anorexia of infection as a mechanism of host defense. Am J Clin Nutr 1979;32:593-596.

77 Wing EJ, Young JB: Acute starvation protects mice against Listeria monocytogenes. Infect Immun 1980;28:771-776.

78 Yang ZJ, Meguid MM: Continuous systemic interleukin-1 alpha infusion suppresses food intake without increasing lateral hypothalamic dopamine activity. Brain Res Bull 1995;36: 417-420.

79 Plata-Salaman CR, Oomura Y, Kai Y: Tumor necrosis factor and interleukin-1 beta: suppression of food intake by direct action in the central nervous system. Brain Res 1988;448: 106-114.

80 Plata-Salaman CR, Borkoski JP: Interleukin-8 modulates feeding by direct action in the central nervous system. Am J Physiol 1993, 265:R877-R882.

81 Reichenberg A, Kraus T, Haack M, Schuld A, Pollmächer T, Yirmiya R: Endotoxin-induced changes in food consumption in healthy volunteers are associated with TNF-alpha and IL-6 secretion. Psychoneuroendocrinology 2002;27:945-956.

82 Turrin NP, Flynn MC, Plata-Salaman CR: Neuropeptide Y counteracts interferon-alpha-induced anorexia. Neuroimmunomodulation 1999;6:361-366.

83 Sudom K, Turrin NP, Hayley S, Anisman H: Influence of chronic interleukin-2 infusion and stressors on sickness behaviors and neurochemical change in mice. Neuroimmunomodulation 2004;11:341-350.

84 Yang ZJ, Koseki M, Meguid MM, Gleason JR, Debonis D: Synergistic effect of rhTNF-alpha and rhIL-1 alpha in inducing anorexia in rats. Am J Physiol 1994;267:R1056-R1064.

85 Debonis D, Meguid MM, Laviano A, Yang ZJ, Gleason JR: Temporal changes in meal number and meal size relationship in response to rHu IL-1 alpha. Neuroreport 1995;6:17521756.

86 Bret-Dibat JL, Creminon C, Couraud JY, Kelley KW, Dantzer R, Kent S: Systemic capsaicin pretreatment fails to block the decrease in food-motivated behavior induced by lipopolysaccharide and interleukin-1beta. Brain Res Bull 1997;42:443-449.

87 Plata-Salaman CR: Meal patterns in response to the intracerebroventricular administration of interleukin-1 beta in rats. Physiol Behav 1994;55:727-733.
88 Stouthard JM, Romijn JA, Van der Poll T, Endert E, Klein S, Bakker PJ, Veenhof $\mathrm{CH}$, Sauerwein HP: Endocrinologic and metabolic effects of interleukin-6 in humans. Am J Physiol 1995;268:E813-E819.

89 Schectman G, Kaul S, Mueller RA, Borden EC, Kissebah AH: The effect of interferon on the metabolism of LDLs. Arterioscler Thromb 1992;12:1053-1062.

90 Aubert A, Goodall G, Dantzer R: Compared effects of cold ambient temperature and cytokines on macronutrient intake in rats. Physiol Behav 1995;57:869-873.

91 Tazi A, Dantzer R, Crestani F, Le Moal M: Interleukin-1 induces conditioned taste aversion in rats: a possible explanation for its pituitary-adrenal stimulating activity. Brain Res 1988;473:369-371.

92 Bluthe RM, Michaud B, Poli V, Dantzer R: Role of IL-6 in cytokine-induced sickness behavior: a study with IL-6 deficient mice. Physiol Behav 2000;70:367-373.

93 Arsenijevic D, Garcia I, Vesin C, Vesin D, Arsenijevic Y, Seydoux J, Girardier L, Ryffel B, Dulloo A, Richard D: Differential roles of tumor necrosis factor-alpha and interferongamma in mouse hypermetabolic and anorectic responses induced by LPS. Eur Cytokine Netw 2000;11:662-668.

94 Uehara A, Ishikawa Y, Okumura T, Okamura K, Sekiya C, Takasugi Y, Namiki M: Indomethacin blocks the anorexic action of interleukin-1. Eur J Pharmacol 1989;170:257-260.

95 Harden LM, du Plessis I, Poole S, Laburn HP: Interleukin-6 and leptin mediate lipopolysaccharide-induced fever and sickness behavior. Physiol Behav 2006;89:146-155.

96 Laye S, Gheusi G, Cremona S, Combe C, Kelley K, Dantzer R, Parnet P: Endogenous brain IL-1 mediates LPS-induced anorexia and hypothalamic cytokine expression. Am J Physiol Regul Integr Comp Physiol 2000; 279:R93-R98

97 Porter MH, Arnold M, Langhans W: TNFalpha tolerance blocks LPS-induced hypophagia but LPS tolerance fails to prevent TNF-alpha-induced hypophagia. Am J Physiol 1998;274:R741-R745.

98 Mrosovsky N, Molony LA, Conn CA, Kluger MJ: Anorexic effects of interleukin 1 in the rat. Am J Physiol 1989;257:R1315-R1321.

99 Weingarten HP: Cytokines and food intake: the relevance of the immune system to the student of ingestive behavior. Neurosci Biobehav Rev 1996;20:163-170.

100 Anforth HR, Bluthe RM, Bristow A, Hopkins S, Lenczowski MJ, Luheshi G, Lundkvist J, Michaud B, Mistry Y, Van Dam AM, Zhen C, Dantzer R, Poole S, Rothwell NJ, Tilders FJ, Wollman EE: Biological activity and brain actions of recombinant rat interleukin-1alpha and interleukin-1beta. Eur Cytokine Netw 1998;9:279-288.

101 Wisse BE: The inflammatory syndrome: the role of adipose tissue cytokines in metabolic disorders linked to obesity. J Am Soc Nephrol 2004;15:2792-2800.
102 Fontana L: Neuroendocrine factors in the regulation of inflammation: excessive adiposity and calorie restriction. Exp Gerontol 2009;44:41-45.

103 Ye J, Keller JN: Regulation of energy metabolism by inflammation: a feedback response in obesity and calorie restriction. Aging ( $\mathrm{Al}-$ bany NY) 2010;2:361-368.

104 Bastard JP, Jardel C, Bruckert E, Blondy P, Capeau J, Laville M, Vidal H, Hainque B: Elevated levels of interleukin 6 are reduced in serum and subcutaneous adipose tissue of obese women after weight loss. J Clin Endocrinol Metab 2000;85:3338-3342.

105 Moschen AR, Molnar C, Geiger S, Graziadei I, Ebenbichler CF, Weiss H, Kaser S, Kaser A, Tilg H: Anti-inflammatory effects of excessive weight loss: potent suppression of adipose interleukin 6 and tumour necrosis factor alpha expression. Gut 2010;59:12591264.

106 Bret-Dibat JL, Bluthe RM, Kent S, Kelley KW, Dantzer R: Lipopolysaccharide and interleukin-1 depress food-motivated behavior in mice by a vagal-mediated mechanism. Brain Behav Immun 1995;9:242-246.

107 Schwartz GJ, Plata-Salaman CR, Langhans W: Subdiaphragmatic vagal deafferentation fails to block feeding-suppressive effects of LPS and IL-1 beta in rats. Am J Physiol 1997; 273:R1193-R1198.

108 Berkowitz DE, Brown D, Lee KM, Emala C, Palmer D, An Y, Breslow M: Endotoxin-induced alteration in the expression of leptin and beta3-adrenergic receptor in adipose tissue. Am J Physiol 1998;274:E992-E997.

109 Finck BN, Kelley KW, Dantzer R, Johnson RW: In vivo and in vitro evidence for the involvement of tumor necrosis factor-alpha in the induction of leptin by lipopolysaccharide. Endocrinology 1998;139:2278-2283.

110 Kirchgessner TG, Uysal KT, Wiesbrock SM, Marino MW, Hotamisligil GS: Tumor necrosis factor-alpha contributes to obesityrelated hyperleptinemia by regulating leptin release from adipocytes. J Clin Invest 1997; 100:2777-2782

111 Grunfeld C, Zhao C, Fuller J, Pollack A, Moser A, Friedman J, Feingold KR: Endotoxin and cytokines induce expression of leptin, the ob gene product, in hamsters. J Clin Invest 1996;97:2152-2157.

112 Sarraf P, Frederich RC, Turner EM, Ma G, Jaskowiak NT, Rivet DJ 3rd, Flier JS, Lowell BB, Fraker DL, Alexander HR: Multiple cytokines and acute inflammation raise mouse leptin levels: potential role in inflammatory anorexia. J Exp Med 1997;185:171-175.

113 Plata-Salaman CR: Central nervous system mechanisms contributing to the cachexiaanorexia syndrome. Nutrition 2000;16: 1009-1012.

114 McCarthy DO: Cytokines and the anorexia of infection: potential mechanisms and treatments. Biol Res Nurs 2000;1:287-298. 
115 Langhans W, Hrupka B: Interleukins and tumor necrosis factor as inhibitors of food intake. Neuropeptides 1999;33:415-424.

116 Yabuuchi K, Minami M, Katsumata S, Satoh M: Localization of type I interleukin-1 receptor mRNA in the rat brain. Brain Res Mol Brain Res 1994;27:27-36.

117 Amaral ME, Barbuio R, Milanski M, Romanatto T, Barbosa HC, Nadruz W, Bertolo MB, Boschero AC, Saad MJ, Franchini KG, Velloso LA: Tumor necrosis factor-alpha activates signal transduction in hypothalamus and modulates the expression of pro-inflammatory proteins and orexigenic/anorexigenic neurotransmitters. J Neurochem 2006;98: 203-212.

118 Kent S, Rodriguez F, Kelley KW, Dantzer R: Reduction in food and water intake induced by microinjection of interleukin-1 beta in the ventromedial hypothalamus of the rat. Physiol Behav 1994;56:1031-1036.

119 Laviano A, Renvyle T, Meguid MM, Yang ZJ, Cangiano C, Rossi Fanelli F: Relationship between interleukin-1 and cancer anorexia. Nutrition 1995;11(suppl):680-683.

120 Laviano A, Gleason JR, Meguid MM, Yang ZJ, Cangiano C, Rossi Fanelli F: Effects of intra-VMN mianserin and IL-1ra on meal number in anorectic tumor-bearing rats. J Investig Med 2000;48:40-48.

121 Gayle D, Ilyin SE, Plata-Salaman CR: Central nervous system IL-1 beta system and neuropeptide Y mRNAs during IL-1 betainduced anorexia in rats. Brain Res Bull 1997;44:311-317.

122 Sonti G, Ilyin SE, Plata-Salaman CR: Neuropeptide Y blocks and reverses interleukin-1 beta-induced anorexia in rats. Peptides 1996;17:517-520.

123 Wang L, Basa NR, Shaikh A, Luckey A, Heber D, St-Pierre DH, Taché Y: LPS inhibits fasted plasma ghrelin levels in rats: role of IL-1 and PGs and functional implications. Am J Physiol Gastrointest Liver Physiol 2006;291:G611-G620.

124 Meguid MM, Fetissov SO, Varma M, Sato T, Zhang L, Laviano A, Rossi-Fanelli F: Hypothalamic dopamine and serotonin in the regulation of food intake. Nutrition 2000;16: 843-857.

125 Doggett NS, Jawaharlal K: Anorectic activity of prostaglandin precursors. Br J Pharmacol 1977;60:417-423

126 Levine AS, Morley JE: The effect of prostaglandins (PGE2 and PGF2 alpha) on food intake in rats. Pharmacol Biochem Behav 1981;15:735-738.

127 Lal J: Possible role of prostaglandins in the regulation of food intake in the newborn rat. Arch Int Pharmacodyn Ther 1984;272:140149.

128 Fargeas MJ, Fioramonti J, Bueno L: Prostaglandin E2: a neuromodulator in the central control of gastrointestinal motility and feeding behavior by calcitonin. Science 1984; 225:1050-1052.
129 Stein J, Zeuzem S, Uphoff K, Laube H: Effects of prostaglandins and indomethacin on gastric emptying in the rat. Prostaglandins 1994;47:31-40.

130 Ruwart MJ, Rush BD: The effects of PGF2 alpha, PGE2 and 16, 16 dimethyl PGE2 on gastric emptying and small intestinal transit in rat. Prostaglandins 1984;28:915-928.

131 Ziemssen T, Kern S: Psychoneuroimmunology - cross-talk between the immune and nervous systems. J Neurol 2007;254(suppl 2):II8-II11.

132 Besedovsky HO, del Rey A, Klusman I, Furukawa H, Monge Arditi G, Kabiersch A: Cytokines as modulators of the hypothalamus-pituitary-adrenal axis. J Steroid Biochem Mol Biol 1991;40:613-618.

133 Berkenbosch F, van Oers J, del Rey A, Tilders F, Besedovsky H: Corticotropin-releasing factor-producing neurons in the rat activated by interleukin-1. Science 1987;238:524526.

134 Sapolsky R, Rivier C, Yamamoto G, Plotsky $\mathrm{P}$, Vale W: Interleukin-1 stimulates the secretion of hypothalamic corticotropin-releasing factor. Science 1987;238:522-524.

135 Navarra P, Tsagarakis S, Faria MS, Rees LH, Besser GM, Grossman AB: Interleukins-1 and -6 stimulate the release of corticotropinreleasing hormone-41 from rat hypothalamus in vitro via the eicosanoid cyclooxygenase pathway. Endocrinology 1991;128:3744.

136 Bernardini R, Kamilaris TC, Calogero AE, Johnson EO, Gomez MT, Gold PW, Chrousos GP: Interactions between tumor necrosis factor-alpha, hypothalamic corticotropinreleasing hormone, and adrenocorticotropin secretion in the rat. Endocrinology 1990; 126:2876-2881.

137 Shibasaki T, Kim YS, Yamauchi N, Masuda A, Imaki T, Hotta M, Demura H, Wakabayashi I, Ling N, Shizume K: Antagonistic effect of somatostatin on corticotropin-releasing factor-induced anorexia in the rat. Life Sci 1988;42:329-334.

138 Uehara A, Sekiya C, Takasugi Y, Namiki M, Arimura A: Anorexia induced by interleukin 1: involvement of corticotropin-releasing factor. Am J Physiol 1989;257:R613-R617.

139 Wang H, Ye J: Regulation of energy balance by inflammation: common theme in physiology and pathology. Rev Endocr Metab Disord 2015;16:47-54.

140 Monteiro R, Azevedo I: Chronic inflammation in obesity and the metabolic syndrome. Mediators Inflamm 2010;2010. pii: 289645.

141 Bastard JP, Maachi M, Lagathu C, Kim MJ, Caron M, Vidal H, Capeau J, Feve B: Recent advances in the relationship between obesity, inflammation, and insulin resistance. Eur Cytokine Netw 2006;17:4-12.
142 Kopp HP, Kopp CW, Festa A, Krzyzanowska K, Kriwanek S, Minar E, Roka R, Schernthaner G: Impact of weight loss on inflammatory proteins and their association with the insulin resistance syndrome in morbidly obese patients. Arterioscler Thromb Vasc Biol 2003;23:1042-1047.

143 O’Rourke RW, Kay T, Lyle EA, Traxler SA, Deveney CW, Jobe BA, Roberts CT Jr, Marks D, Rosenbaum JT: Alterations in peripheral blood lymphocyte cytokine expression in obesity. Clin Exp Immunol 2006;146:39-46.

144 Di Gregorio GB, Hensley L, Lu T, Ranganathan G, Kern PA: Lipid and carbohydrate metabolism in mice with a targeted mutation in the IL- 6 gene: absence of development of age-related obesity. Am J Physiol Endocrinol Metab 2004;287:E182-E187.

145 Garcia MC, Wernstedt I, Berndtsson A, Enge M, Bell M, Hultgren O, Horn M, Ahrén B, Enerback S, Ohlsson C, Wallenius V, Jansson JO: Mature-onset obesity in interleukin-1 receptor I knockout mice. Diabetes 2006;55:1205-1213.

146 McGillicuddy FC, Reynolds CM, Finucane O, Coleman E, Harford KA, Grant C, Sergi D, Williams LM, Mills KH, Roche HM: Long-term exposure to a high-fat diet results in the development of glucose intolerance and insulin resistance in interleukin-1 receptor I-deficient mice. Am J Physiol Endocrinol Metab 2013;305:E834-E844.

147 Netea MG, Joosten LA, Lewis E, Jensen DR, Voshol PJ, Kullberg BJ, Tack CJ, van Krieken H, Kim SH, Stalenhoef AF, van de Loo FA, Verschueren I, Pulawa L, Akira S, Eckel RH, Dinarello CA, van den Berg W, van der Meer JW: Deficiency of interleukin-18 in mice leads to hyperphagia, obesity and insulin resistance. Nat Med 2006;12:650-656.

148 Matsuki T, Horai R, Sudo K, Iwakura Y: IL-1 plays an important role in lipid metabolism by regulating insulin levels under physiological conditions. J Exp Med 2003;198:877888.

149 Somm E, Henrichot E, Pernin A, Juge-Aubry CE, Muzzin P, Dayer JM, Nicklin MJ, Meier CA: Decreased fat mass in interleukin-1 receptor antagonist-deficient mice: impact on adipogenesis, food intake, and energy expenditure. Diabetes 2005;54:35033509.

150 Horai R, Asano M, Sudo K, Kanuka H, Suzuki M, Nishihara M, Takahashi M, Iwakura Y: Production of mice deficient in genes for interleukin (IL)-1alpha, IL-1beta, IL-1alpha/beta, and IL-1 receptor antagonist shows that IL-1beta is crucial in turpentineinduced fever development and glucocorticoid secretion. J Exp Med 1998;187:14631475.

151 Andersson N, Strandberg L, Nilsson S, Ljungren O, Karlsson MK, Mellström D, Lorentzon M, Ohlsson C, Jansson JO: Variants of the interleukin-1 receptor antagonist gene are associated with fat mass in men. Int J Obes (Lond) 2009;33:525-533. 
152 Um JY, Rim HK, Kim SJ, Kim HL, Hong SH: Functional polymorphism of IL-1 alpha and its potential role in obesity in humans and mice. PLoS One 2011;6:e29524.

153 Lee JH, Kwon YD, Hong SH, Jeong HJ, Kim HM, Um JY: Interleukin-1 beta gene polymorphism and traditional constitution in obese women. Int J Neurosci 2008;118:793805.

154 Strandberg L, Lorentzon M, Hellqvist A, Nilsson S, Wallenius V, Ohlsson C, Jansson JO: Interleukin-1 system gene polymorphisms are associated with fat mass in young men. J Clin Endocrinol Metab 2006;91: 2749-2754.

155 Strandberg L, Mellstrom D, Ljunggren O, Grundberg E, Karlsson MK, Holmberg AH, Orwoll ES, Eriksson AL, Svedberg J, Bengtsson M, Ohlsson C, Jansson JO: IL6 and IL1B polymorphisms are associated with fat mass in older men: the MrOS Study Sweden. Obesity (Silver Spring) 2008;16:710-713 .

156 Stephens JW, Hurel SJ, Cooper JA, Acharya J, Miller GJ, Humphries SE: A common functional variant in the interleukin-6 gene is associated with increased body mass index in subjects with type 2 diabetes mellitus. Mol Genet Metab 2004;82:180-186.

157 Goyenechea E, Parra D, Martinez JA: Impact of interleukin $6-174 \mathrm{G}>\mathrm{C}$ polymorphism on obesity-related metabolic disorders in people with excess in body weight. Metabolism 2007;56:1643-1648.

158 Andersson N, Strandberg L, Nilsson S, Adamovic S, Karlsson MK, Ljunggren O, Mellström D, Lane NE, Zmuda JM, Nielsen C, Orwoll E, Lorentzon M, Ohlsson C, Jansson JO; Osteoporotic Fractures in Men MrOS Research Group: A variant near the interleukin-6 gene is associated with fat mass in Caucasian men. Int J Obes (Lond) 2010;34:1011-1019.

159 Qi L, Zhang C, van Dam RM, Hu FB: Interleukin-6 genetic variability and adiposity: associations in two prospective cohorts and systematic review in 26,944 individuals. $J$ Clin Endocrinol Metab 2007;92:3618-3625.

160 Wolford JK, Colligan PB, Gruber JD, Bogardus C: Variants in the interleukin 6 receptor gene are associated with obesity in Pima Indians. Mol Genet Metab 2003;80:338-343.
161 Fonseka TM, Tiwari AK, Goncalves VF, Lieberman JA, Meltzer HY, Goldstein BI, Kennedy JL, Kennedy SH, Müller DJ: The role of genetic variation across IL-1beta, IL2, IL-6, and BDNF in antipsychotic-induced weight gain. World J Biol Psychiatry 2015; 16:45-56.

162 Speliotes EK, Willer CJ, Berndt SI, Monda $\mathrm{KL}$, et al: Association analyses of 249,796 individuals reveal 18 new loci associated with body mass index. Nat Genet 2010;42:937948.

163 Kronfol Z, Remick DG: Cytokines and the brain: implications for clinical psychiatry. Am J Psychiatry 2000;157:683-694.

164 Miller BJ, Buckley P, Seabolt W, Mellor A, Kirkpatrick B: Meta-analysis of cytokine alterations in schizophrenia: clinical status and antipsychotic effects. Biol Psychiatry 2011;70:663-671.

165 Bian Q, Kato T, Monji A, Hashioka S, Mizoguchi $\mathrm{Y}$, Horikawa $\mathrm{H}$, Kanba S: The effect of atypical antipsychotics, perospirone, ziprasidone and quetiapine on microglial activation induced by interferon-gamma. Prog Neuropsychopharmacol Biol Psychiatry 2008;32:42-48.

166 Kato T, Monji A, Hashioka S, Kanba S: Risperidone significantly inhibits interferongamma-induced microglial activation in vitro. Schizophr Res 2007;92:108-115.

167 Park SW, Lee CH, Lee JG, Kim LW, Shin BS, Lee BJ, Kim YH: Protective effects of atypical antipsychotic drugs against $\mathrm{MPP}^{+}$-induced oxidative stress in PC12 cells. Neurosci Res 2011;69:283-290.

168 Schroeter ML, Abdul-Khaliq H, Fruhauf S, Höhne R, Schick G, Diefenbacher A, Blasig IE: Serum S100B is increased during early treatment with antipsychotics and in deficit schizophrenia. Schizophr Res 2003;62:231236.

169 Qi LY, Xiu MH, Chen da C, Wang F, Kosten TA, Kosten TR, Zhang XY: Increased serum S100B levels in chronic schizophrenic patients on long-term clozapine or typical antipsychotics. Neurosci Lett 2009;462:113117.
170 Ling SH, Tang YL, Jiang F, Wiste A, Guo SS Weng YZ, Yang TS: Plasma S-100B protein in Chinese patients with schizophrenia: comparison with healthy controls and effect of antipsychotics treatment. J Psychiatr Res 2007;41:36-42.

171 Crowle AJ, Douvas GS, May MH: Chlorpromazine: a drug potentially useful for treating mycobacterial infections. Chemotherapy 1992;38:410-9.

172 Moots RJ, Al-Saffar Z, Hutchinson D, Golding SP, Young SP, Bacon PA, McLaughlin PJ: Old drug, new tricks: haloperidol inhibits secretion of proinflammatory cytokines. Ann Rheum Dis 1999;58:585-587.

173 Zhang XY, Zhou DF, Cao LY, Wu GY, Shen YC: Cortisol and cytokines in chronic and treatment-resistant patients with schizophrenia: association with psychopathology and response to antipsychotics. Neuropsychopharmacology 2005;30:1532-1538.

174 Chase KA, Rosen C, Gin H, Bjorkquist O, Feiner B, Marvin R, Conrin S, Sharma RP: Metabolic and inflammatory genes in schizophrenia. Psychiatry Res 2015;225 208-211.

175 Sirota P, Hadi E, Djaldetti M, Bessler H: Difference in inflammatory cytokine production by mononuclear cells from obese and non-obese schizophrenic patients. Acta Psychiatr Scand 2015;132:301-305.

176 Kluge M, Schuld A, Schacht A, Himmerich H, Dalal MA, Wehmeier PM, Hinze-Selch D, Kraus T, Dittmann RW, Pollmächer T: Effects of clozapine and olanzapine on cytokine systems are closely linked to weight gain and drug-induced fever. Psychoneuroendocrinology 2009;34:118-128.

177 Song X, Fan X, Li X, Zhang W, Gao J, Zhao J, Harrington A, Ziedonis D, Lv L: Changes in pro-inflammatory cytokines and body weight during 6-month risperidone treatment in drug naive, first-episode schizophrenia. Psychopharmacology (Berl) 2014; 231:319-325.

178 Klemettila JP, Kampman O, Seppala N, Viikki M, Hämäläinen M, Moilanen E, Leinonen E: Cytokine and adipokine alterations in patients with schizophrenia treated with clozapine. Psychiatry Res 2014;218 277-283. 